\title{
Thermally Stable Nanocrystalline Steel
}

\author{
CHRISTOPHER NEIL HULME-SMITH, SHGH WOEI OOI, \\ and HARSHAD K.D.H. BHADESHIA
}

Two novel nanocrystalline steels were designed to withstand elevated temperatures without catastrophic microstructural changes. In the most successful alloy, a large quantity of nickel was added to stabilize austenite and allow a reduction in the carbon content. A $50 \mathrm{~kg}$ cast of the novel alloy was produced and used to verify the formation of nanocrystalline bainite. Synchrotron X-ray diffractometry using in situ heating showed that austenite was able to survive more than 1 hour at $773 \mathrm{~K}\left(500^{\circ} \mathrm{C}\right)$ and subsequent cooling to ambient temperature. This is the first reported nanocrystalline steel with high-temperature capability.

DOI: $10.1007 / \mathrm{s} 11661-017-4248-\mathrm{x}$

(C) The Author(s) 2017. This article is an open access publication

\section{INTRODUCTION}

NanOCRYSTALline steels, commonly referred to as superbainite, have been the subject of a large number of studies since their development by Caballero et $a l^{[1]}$ due to their combination of strength and toughness, achieved in large volumes with neither rapid cooling nor severe deformation. ${ }^{[1-9]}$ The structure consists mostly of alternating thin plates of bainitic ferrite, $\alpha_{b}$, and retained austenite, $\gamma_{r}$, with a small fraction of retained austenite blocks forming the residue of the sample. The austenite films and bainite plates are typically below $50 \mathrm{~nm}$ in width, providing a potent strengthening mechanism without compromising toughness. The retained austenite is able to accommodate a large amount of plastic work by either one of or both dislocation glide and the formation of stress-induced martensite.

Nanocrystalline steels represent a formidable combination of mechanical properties; their transformation ultimately relies on the addition of a large quantity of carbon. Carbon serves to depress both the martensite-start temperature, $M_{s}$, and the bainite-start temperature, $B_{s}$, but the former more than the latter. ${ }^{[2]}$ There is then a sufficiently wide temperature range in bainite that may form with ever finer platelets as the transformation temperature is lowered.

The large carbon content is further enhanced in the retained austenite due to partitioning after the bainitic

CHRISTOPHER NEIL HULME-SMITH, SHGH WOEI OOI, and HARSHAD K.D.H. BHADESHIA are with the Department of Materials Science and Metallurgy, University of Cambridge, 27 Charles Babbage Road, Cambridge, CB3 0FS, UK. Contact e-mail: cns28@cam.ac.uk

Manuscript submitted January 9, 2017.

Article published online August 9, 2017 transformation. At temperatures where the atomic mobility of carbon atoms is sufficient, there will then be a tendency for the austenite to decompose into a mixture of ferrite and cementite. Many studies have observed a carbon supersaturation with respect to cementite in both austenite $e^{[5,6,10-15]}$ and ferrite. $^{[12,13,15-19]}$ There is therefore a large driving force for the formation of cementite in both phases. Rapid decomposition of austenite into carbides and ferrite has been observed in nanocrystalline steels upon heating. ${ }^{[20,21]}$ The resulting loss of austenite compromises both the strength and toughness of the steel and hence it is unsuitable for service at elevated temperatures.

The aim of the current work was to design new nanocrystalline steel alloys that are able to tolerate exposure to high temperatures while retaining an acceptable level of strength and toughness.

\section{ALLOY DESIGN}

Two approaches were considered to develop novel alloys: an extension of previous work ${ }^{[22]}$ to introduce as many atoms that are insoluble in cementite as possible and a new concept to minimize the carbon content while still obtaining the desired microstructure.

Thermodynamic modeling was conducted using the calculation software MTDATA version 4.73 from the National Physical Laboratory, Teddington, U. K. ${ }^{[23]}$ with various thermodynamic databases. ${ }^{[24,25]}$ Due to the large solute concentrations envisaged, $B_{s}$ temperatures were calculated using the program MTTTData*.[23,25,26] html.

*http://www.msm.cam.ac.uk/map/steel/programs/MTTTDATA. 
$M_{S}$ temperatures were calculated using an artificial neural network via the software Neuromat Model Manager ${ }^{[27]}$ and using a publicly available database**.[28] Where a

**http://www.msm.cam.ac.uk/map/data/materials/Ms_data_2004.html.

composition lay within its specified limits, $M_{s}$ was calculated also using the program MUCG83 ${ }^{\dagger}$. $^{29]}$

${ }^{\dagger}$ http://www.msm.cam.ac.uk/map/steel/programs/mucg83.html.

\section{A. Alloy 1}

In a previous study it was found that a large concentration of silicon, which is insoluble in cementite, was effective in delaying the thermal decomposition of retained austenite in a nanocrystalline steel to exceptionally high temperatures during continuous heating. ${ }^{[22]}$ The alloy included manganese to suppress $M_{S}$ and $B_{s}$ and for hardenability (Fe-1.037 C-1.97 Mn-3.89 $\mathrm{Si}-1.43 \mathrm{Al}$ (wt pct)). Manganese is effective in both roles as it reduces the driving force for the transformation of austenite to ferrite, $\Delta G^{\gamma \rightarrow \alpha}$. However, manganese is also extensively soluble in cementite and so could conceivably favor cementite precipitation whereas nickel would not (Figure 1). A new alloy, Alloy 1, was therefore developed to replace manganese with nickel while otherwise leaving the composition substantially unchanged.

Thermodynamic modeling showed that a nickel content of $3.3 \mathrm{wt}$ pet was appropriate to maintain similar $B_{S}$ and $M_{s}$ to the alloy studied previously. Other solutes were left substantially unchanged with the exception of the silicon content, which was increased to $4.0 \mathrm{wt}$ pct. The calculated equilibrium phase fractions for Alloy 1 (Figure 2) shows a wide temperature range that allows the alloy to be austenitized, which is necessary to develop a homogeneous bainitic structure. The designed composition of Alloy 1 (Table I) is within the limits of the program MUCG, which predicted an $M_{s}$ of $515 \mathrm{~K}$ $\left(242^{\circ} \mathrm{C}\right)$. The prediction of the artificial neural network

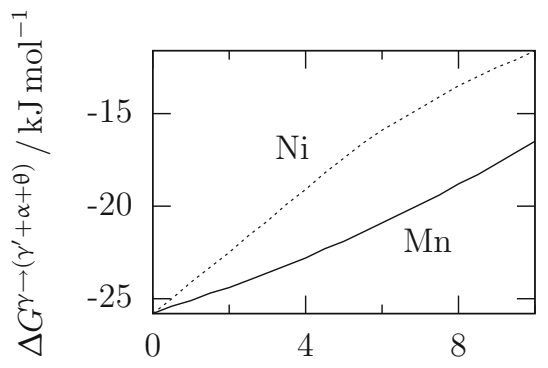

Substitutional element content / wt pct

Fig. 1-Driving force for the decomposition of austenite, $\gamma$, to a paraequilibrium mixture of carbon-depleted austenite, $\gamma^{\prime}$, ferrite, $\alpha$ and cementite, $\theta$, calculated in Fe-1.0 wt pct C- $x$ at $773.15 \mathrm{~K}(500,00$ $\left.{ }^{\circ} \mathrm{C}\right) .{ }^{[23,24]}$

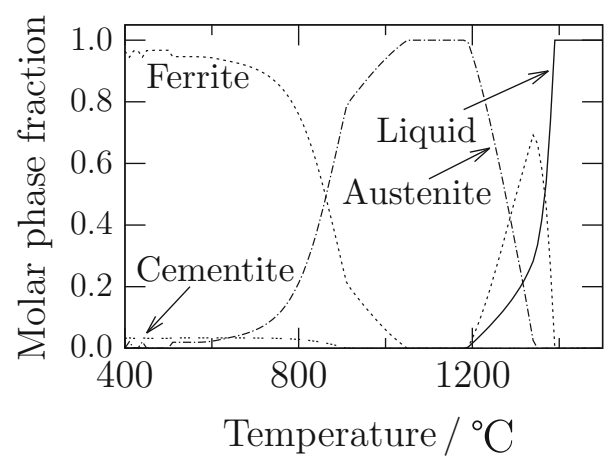

Fig. 2-Calculated equilibrium phase fractions for Alloy 1 allowing liquid, austenite, ferrite, and cementite only. ${ }^{[23,25]}$ No other phases were anticipated to form.

was $423 \pm 30 \mathrm{~K}\left(150 \pm 30^{\circ} \mathrm{C}\right)$. There is no clear reason for this discrepancy and $M_{s}$ was determined to be $516 \mathrm{~K}$ $\left(243{ }^{\circ} \mathrm{C}\right)$ using dilatometry and the offset method. The program MTTTData calculated $B_{s}$ to be $623 \mathrm{~K}\left(350{ }^{\circ} \mathrm{C}\right)$ (Figure 2).

\section{B. Alloy 2}

Although previous work $^{[22]}$ has shown that the addition of large amount of cementite-insoluble elements can delay the thermal decomposition, it is unlikely that such an approach can sufficiently suppress cementite precipitation: ultimately, a mixture of ferrite and cementite is required by equilibrium. A novel approach was therefore considered: to minimize the carbon content of retained austenite and thereby reduce the driving force for the precipitation of carbides. Significant quantities of substitutional austenite stabilizer (other than manganese) must then be added to both prevent ferrite formation at high temperatures and to reduce the amount of carbon enrichment in austenite during the bainite transformation. Nickel, which is a powerful substitutional austenite stabilizer that can be exploited for this purpose. ${ }^{[30]}$

Thermodynamic calculations showed that the composition listed in Table I can be fully austenitized (Figure 3 ) and has a calculated $B_{s}$ of $643 \mathrm{~K}\left(370{ }^{\circ} \mathrm{C}\right)$ and $M_{s}$ of $363 \mathrm{~K}\left(90^{\circ} \mathrm{C}\right) \cdot{ }^{[23,25,26]}$ The neural network model predicts an $M_{s}$ of $413 \mathrm{~K}\left(160{ }^{\circ} \mathrm{C}\right) .{ }^{[27,28]}$ These values are consistent with previously reported nanocrystalline bainitic steels. ${ }^{[1-6]}$ The carbon content of $0.4 \mathrm{wt}$ pct was chosen to provide a suitable interval between $B_{s}$ and $M_{S}$ such that a large volume fraction of bainite may be formed. ${ }^{[30]}$ Besides iron, carbon, and nickel, Alloy 2 includes aluminum to both accelerate the bainite transformation and provide some resistance to cementite precipitation, cobalt to further accelerate the bainite transformation, and small amounts of manganese and molybdenum to tie up sulfur and phosphorus impurities, respectively, but in quantities small enough not to have other metallurgical consequences. ${ }^{[23,24]}$ The level of aluminum is limited so that the $B_{s}$ and $M_{s}$ remain suppressed to temperatures where nanostructured bainite can be obtained (Table I). 
Table I. Designed Compositions of New Alloys

\begin{tabular}{lccccccc}
\hline & C & Mn & Al & Ni & Si & Co \\
\hline Alloy 1 & 0.7 & 0.02 & 1.4 & 3.3 & 4.0 & -13.0 \\
Alloy 2 & 0.4 & 0.15 & 2.5 & 13.0 & - & 4.0 \\
\hline
\end{tabular}

All Values are in wt pct.

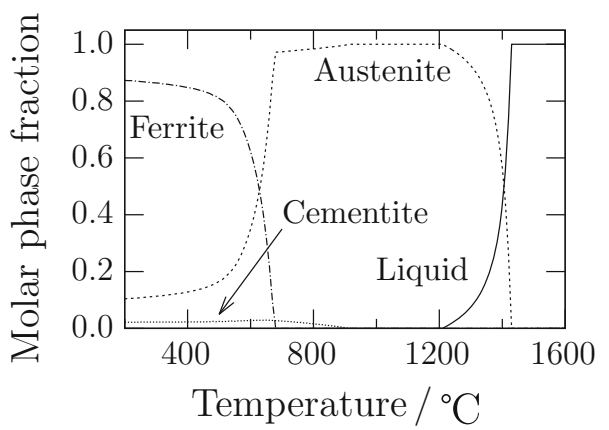

Fig. 3-Calculated equilibrium phase fractions for Alloy 2 allowing liquid, austenite, ferrite, and cementite only. ${ }^{[23,25]}$ No other phases were anticipated to form.

A lower bound for the amount of carbon in solution in retained austenite is derived using the thermodynamic quantity $x_{T_{0}^{\prime}}$, the carbon content at which austenite and ferrite have the same free energy at a given temperature once the strain energy of transformation has been accounted for. Should the carbon content of austenite reach this value, further diffusionless transformation to ferrite is thermodynamically impossible. The expected $x_{T_{0}}$ of Alloy 2 is significantly lower at a given temperature than that of Alloy 1 (Figure 4).

Apart from limiting the amount of carbon enrichment in austenite, a high nickel content stabilizes the retained austenite with respect to ferrite. This is especially important during exposure to elevated temperature when carbides are able to precipitate. The resulting depletion of carbon in the retained austenite has been shown to lead to the formation of more ferrite, both during isothermal holding and during subsequent cooling. ${ }^{[20,21]}$ It is expected that the high nickel content of Alloy 2 will prevent this transformation and allow the alloy to avoid carbide precipitation during thermal exposure.

\section{EXPERIMENTAL METHODS}

\section{A. As-transformed Microstructures}

Samples of both alloys, measuring $(10 \mathrm{~mm} \times 10 \mathrm{~mm} \times$ $80 \mathrm{~mm})$ and of the measured composition given in Table II were heated in a vacuum tube furnace to 1273 $\mathrm{K}\left(1000{ }^{\circ} \mathrm{C}\right)$ to form austenite. After 30 minutes, the samples were removed and agitated in air until no glowing was observed, at which point, they were assumed to be no hotter than $798 \mathrm{~K}\left(525^{\circ} \mathrm{C}\right) .{ }^{[31]}$ They were then transferred to a high-precision oven at $523 \mathrm{~K}$ $\left(250{ }^{\circ} \mathrm{C}\right.$ ) for 1 day (Alloy 1$)$ or for 14 days (Alloy 2). The resulting microstructures (Figure 5) show that a

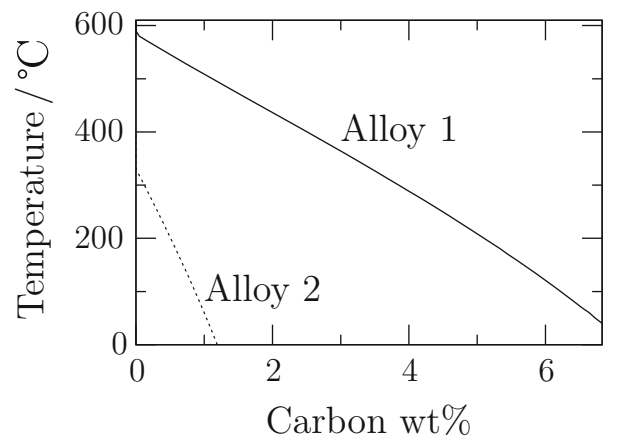

Fig. 4-The temperature-dependent values of $x_{T^{\prime}}$ for both Alloy 1 and Alloy 2 calculated MTTTData. ${ }^{[23,25,26]}$ Data are calculated only for $273 K<T<B_{S}\left(0^{\circ} C<T<B_{S}\right)$. Alloy 2 is expected to form retained austenite with a lower carbon content than Alloy 1 at a given transformation temperature.

homogeneous microstructure of nanocrystalline bainite has formed.

Representative SEM images were analyzed using the software ImageJ to derive the grain widths of the austenite and ferrite films using the mean lineal intercept method. ${ }^{[32]}$ Twenty measurements were made for each phase in each sample. The grains were assumed to be plate-shaped and the measured intercept was multiplied by a stereological correction factor of $\frac{\pi}{2} \cdot{ }^{[3,34]}$

\section{B. Thermal Stability}

The thermal stability of both alloys was assessed by synchrotron X-ray diffractometry with in situ heating. Experiments were performed at beamline I12 at Diamond Light Source, Didcot, U. K. $3 \mathrm{~mm}$ diameter rods were sealed into glass ampoules filled with argon, austenitized at $1273 \mathrm{~K}\left(1000{ }^{\circ} \mathrm{C}\right)$ for 30 minutes, and transformed to bainite at $523 \mathrm{~K}\left(250{ }^{\circ} \mathrm{C}\right)$. The samples of Alloy 1 were allowed to transform for 1 day and those of Alloy 2 for 14 days. Tempering was performed using a bespoke halogen lamp furnace with X-ray-transparent windows. The temperature was controlled using a thermocouple on the surface of the sample and close to the X-ray beam. The windows for the diffracted beam had a radius of $10 \mathrm{~mm}$ and were approximately $100 \mathrm{~mm}$ from the center of the sample. X-rays that did not pass through the windows were heavily attenuated. $2 \theta$ was thus limited to approximately $5.7 \mathrm{deg}$. A photon energy of $120 \mathrm{keV}$ (equivalent to a wavelength of $0.103 \AA$ ) was chosen to ensure enough peaks were detected to allow Rietveld refinement to be performed.

X-ray detection was attained by a Thales Pixium RF 4343 large-area 2D detector with pixels $148 \mu \mathrm{m}^{2}$ 
Table II. Compositions of Novel Alloys, as Measured During Cast Production

\begin{tabular}{lccccccr}
\hline & C & Mn & Al & Ni & Si & Co & Mo \\
\hline Alloy 1 & 0.72 & 0.02 & 1.38 & 3.40 & 3.88 & 0.20 \\
Alloy 2 & 0.45 & 0.15 & 2.63 & 13.2 & 0.03 & 3.99 & 0.30 \\
\hline
\end{tabular}

All Values are in wt pct.

Table III. Stereologically Corrected Grain Widths, Measured Perpendicular to the Long Axis of Each Plate for Samples Transformed at $523 \mathrm{~K}\left(250^{\circ} \mathrm{C}\right)$

\begin{tabular}{lrr}
\hline & \multicolumn{2}{c}{ Grain Size $/ \mathrm{nm}$} \\
\cline { 2 - 3 } & \multicolumn{1}{c}{$\gamma_{\mathrm{r}}$} & \multicolumn{1}{c}{$\alpha_{\mathrm{b}}$} \\
\hline Alloy 1 & $70 \pm 30$ & $80 \pm 50$ \\
Alloy 2 & $100 \pm 30$ & $140 \pm 50$ \\
\hline
\end{tabular}

Errors are the standard deviation of the individual measurements.

positioned perpendicular to the X-ray beam and 1500 $\mathrm{mm}$ from the sample. The line broadening behavior of the beamline was calibrated using a ceria standard. Calibrations were performed at both the beginning and the end of the experiment after Hart et al. ${ }^{[35]}$

The X-ray beam size was optimized to $0.5 \mathrm{~mm}^{2}$, which gives sufficient angular resolution to resolve all peaks while maintaining the maximum practicable detected intensity, so allowing data to be recorded as often as possible. Data were collected every 4 seconds.

Samples were heated from ambient temperature to $773 \mathrm{~K}\left(500{ }^{\circ} \mathrm{C}\right)$ at $10 \mathrm{~K} \min ^{-1}\left(10{ }^{\circ} \mathrm{C} \mathrm{min}^{-1}\right)$. The temperature was maintained until it was deemed that no further change in diffraction rings was likely. The samples were then allowed to cool in air to ambient temperature at $20 \mathrm{~K} \mathrm{~min}^{-1}\left(20{ }^{\circ} \mathrm{C} \mathrm{m^{-1 }}\right)$.

Data were acquired as 24-bit TIFF images, which were integrated using graphical analysis software Fit2D..$^{[36,37]}$ Integrated data were then subjected to Rietveld refinement analysis using the software Materials Analysis Using Diffraction (MAUD). ${ }^{[38-40]}$ For the purposes of Rietveld analysis, the material was assumed to consist of austenite and ferrite only. A fifth-order polynomial background function, incident X-ray intensity, the lattice parameters, crystallite size, and microstrain of both phases, and the volume fraction of austenite were allowed to refine. The volume fraction of ferrite was set to be the residue of the sample.

\section{RESULTS}

\section{A. Measured Composition}

Chemical analysis during production resulted in the measured compositions in Table II.

\section{B. As-transformed Microstructures}

It may be seen that both alloys produce homogeneous, nanocrystalline bainitic structures (Figure 5).
Analysis of the width of retained austenite films and bainitic ferrite platelets showed that both phases were finer in Alloy 1 than Alloy 2 (Table III), but that the difference was well within the uncertainty of the measurement.

\section{Thermal Stability}

Inspection of the integrated data shows that while all peaks initially shift to lower Bragg angles due to thermal expansion during heating, the austenite peaks in Alloy 1 shift suddenly to slightly higher Bragg angles after approximately $3 \mathrm{ks}$ [equivalent to the sample reaching $\left.773 \mathrm{~K} \quad\left(500{ }^{\circ} \mathrm{C}\right)\right]$ and thereupon rapidly disappear (Figure 6(a)). The ferrite peaks simultaneously become more intense and additional peaks corresponding to carbides appear. All carbide and ferrite peaks shift to higher Bragg angles during cooling. In Alloy 2, all peaks initially shift to lower Bragg angles, but the austenite peaks do not then disappear (Figure 6(b)). Both austenite and ferrite peaks shift to higher Bragg angles during cooling. Austenite peaks are still present at the conclusion of the experiment, at which time the sample is at ambient temperature.

Closer inspection of the Rietveld refinement results for austenite shows a large contraction in the austenite lattice parameter of Alloy 1, which is immediately followed by the reduction of the austenite volume fraction until austenite is almost lost from the material (Figure 7(a)). In Alloy 2, the austenite lattice parameter drops slightly at $2.8 \mathrm{ks}$ to a new steady value. Similarly, the volume fraction decreases to a new steady value (Figure 7(b)). It is clear that austenite in Alloy 2 has survived the heat treatment. In both alloys, peaks that formed during tempering could be attributed to cementite, consistent with previous observations in literature. ${ }^{[41]}$

Examination of the microstructures of the alloys after the in situ experiments confirm the XRD findings that austenite is lost in Alloy 1 but persists, albeit at a lower volume fraction, in Alloy 2. The as-transformed microstructure of Alloy 1 has been completely destroyed (Figure 8(a)) but are still present in Alloy 2 (Figure 8(b)). A close examination of austenite films in a sample of Alloy 2 transformed to bainite at $498 \mathrm{~K}\left(225^{\circ} \mathrm{C}\right)$ and exposed to the same tempering treatment reveals that some of them contain martensite plates, $\alpha^{\prime}$ (Figure 8(c)). Such features were not observed during extensive examination of as-transformed Alloy 2. 

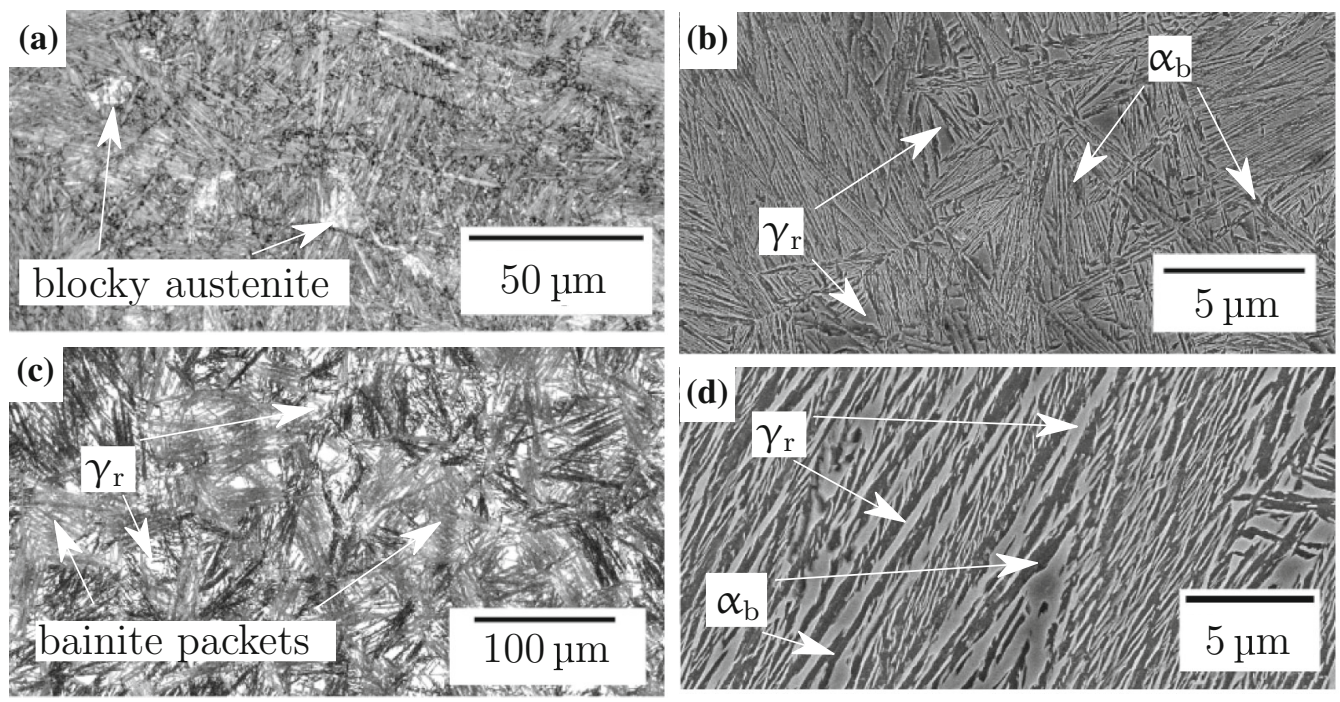

Fig. 5- Structures after transformation of $(a, b)$ Alloy 1 and $(c, d)$ Alloy 2. The high-magnification images demonstrate that the transformation product is nanocrystalline bainite in both cases and the low-magnification micrographs show that the structures of both alloys are homogeneous.
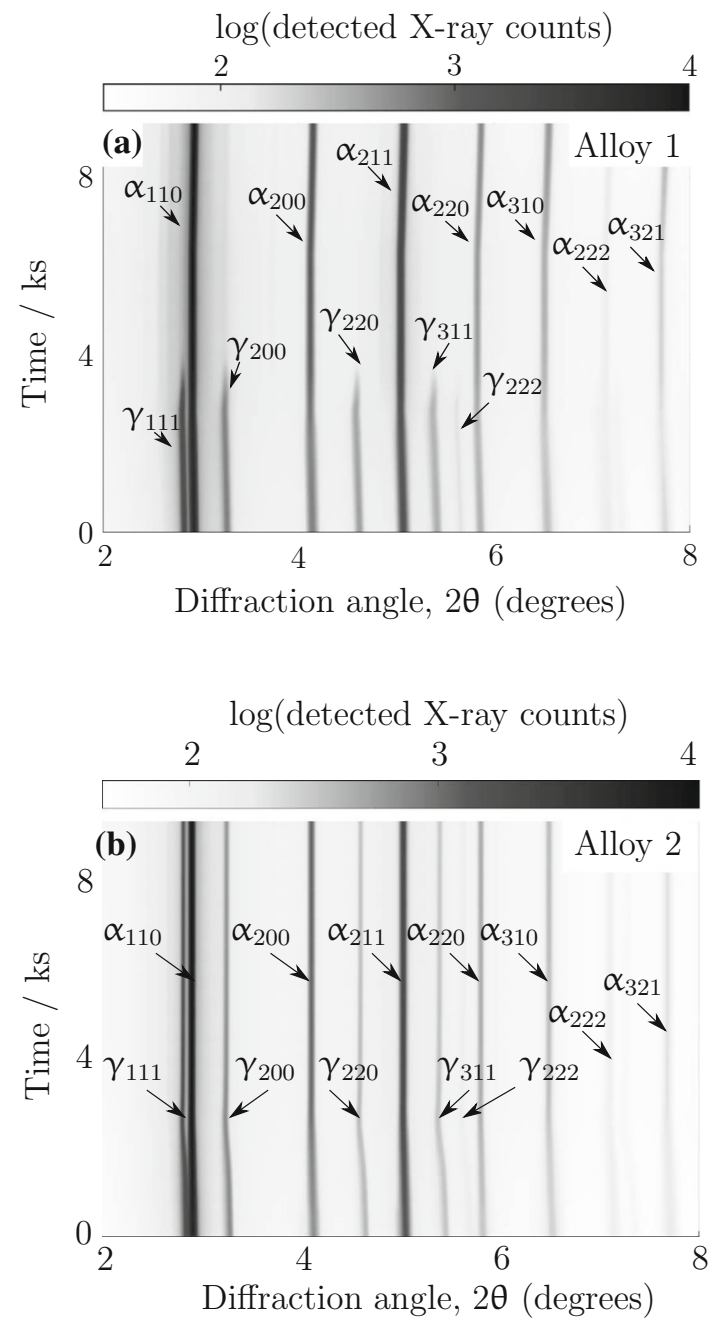

Fig. 6-Integrated XRD data for tempering experiments at Diamond Light Source. (a) the peaks attributed to austenite disappear upon heating in Alloy 1 , but $(b)$ persist throughout the experiment in Alloy 2 .

\section{DISCUSSION}

The as-transformed structures are nanocrystalline bainite, consistent with the calculated transformation properties. The larger crystal size of Alloy 2 (Table III) is also in line with bainite transformation theory as its lower carbon content renders the parent austenite weaker than that of Alloy 1. This allows more plastic deformation to occur and bainitic ferrite plates are able to grow larger before being stifled by work hardening. The composition of Alloy 2 also aids this effect, since both nickel and aluminum lower the cross-slip energy in austenite while silicon increases it. ${ }^{[42,43]}$ This reduces the rate of work hardening. Although the grain sizes in Alloy 2 appear to be larger than those typically associated with nanocrystalline bainitic steel, the transformation has taken place at a temperature consistent with such alloys in literature and the structure is certainly bainitic. Furthermore, the difference between grain size of Alloy 2 and those typical of steels in previously published work is within the error of the current measurements. The authors therefore consider Alloy 2 to be a nanocrystalline bainitic steel.

The apparent thermal stability of Alloy 2 validates the design process. Analysis of the carbide peaks identifies cementite as the main carbide, accounting for almost all additional peaks, consistent with the absence of silicon.

Tensile test results indicate that the 0.2 pct proof stress of Alloy 1 increases from $1490 \pm 50 \mathrm{MPa}$ to 1767 $\mathrm{MPa}$ as a result of tempering at $723 \mathrm{~K}\left(450{ }^{\circ} \mathrm{C}\right)$ for 8 days (two samples of each condition were tested, but proof stress could only be assessed in one of the tempered samples, so no experimental uncertainty may be assessed). In Alloy 2, the same heat treatment caused a rise in 0.2 pct proof stress from $1011 \pm 5$ to $1603 \pm 12$ $\mathrm{MPa}$. Although tempering is usually expected to soften material, the current data are consistent with previously reported tempering experiments in nanocrystalline bainitic steels, where ductile austenite decomposes into less-ductile ferrite and carbides without significant grain 


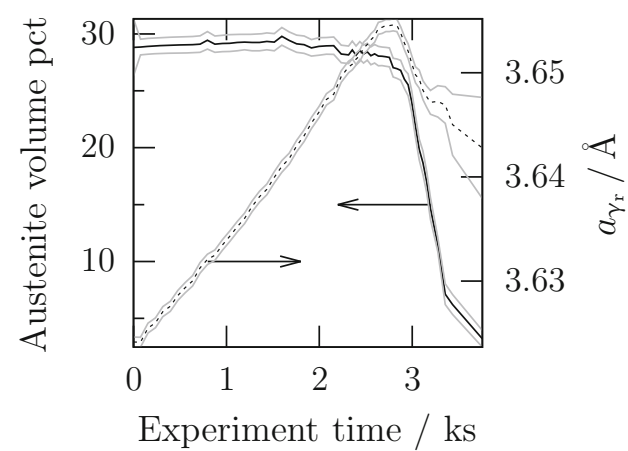

(a)

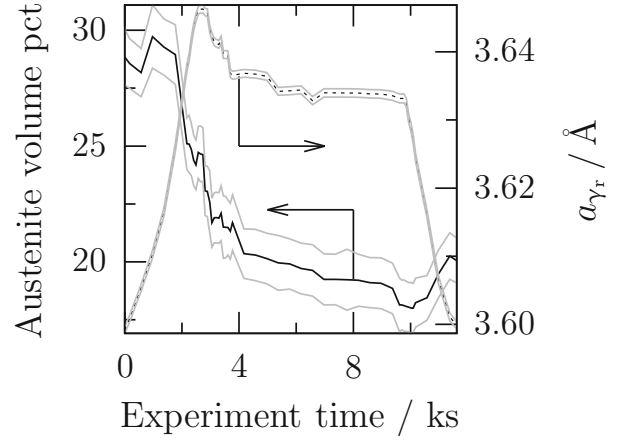

(b)

Fig. 7-Austenite volume fractions and lattice parameters derived using Rietveld refinement from the synchrotron XRD data for (a) Alloy 1 and (b) Alloy 2. The austenite in Alloy 1 undergoes thermal expansion before contracting sharply whereupon it is lost. In Alloy 2 the austenite contracts slightly and partially transforms. The remaining austenite then persists for the remainder of the experiment.
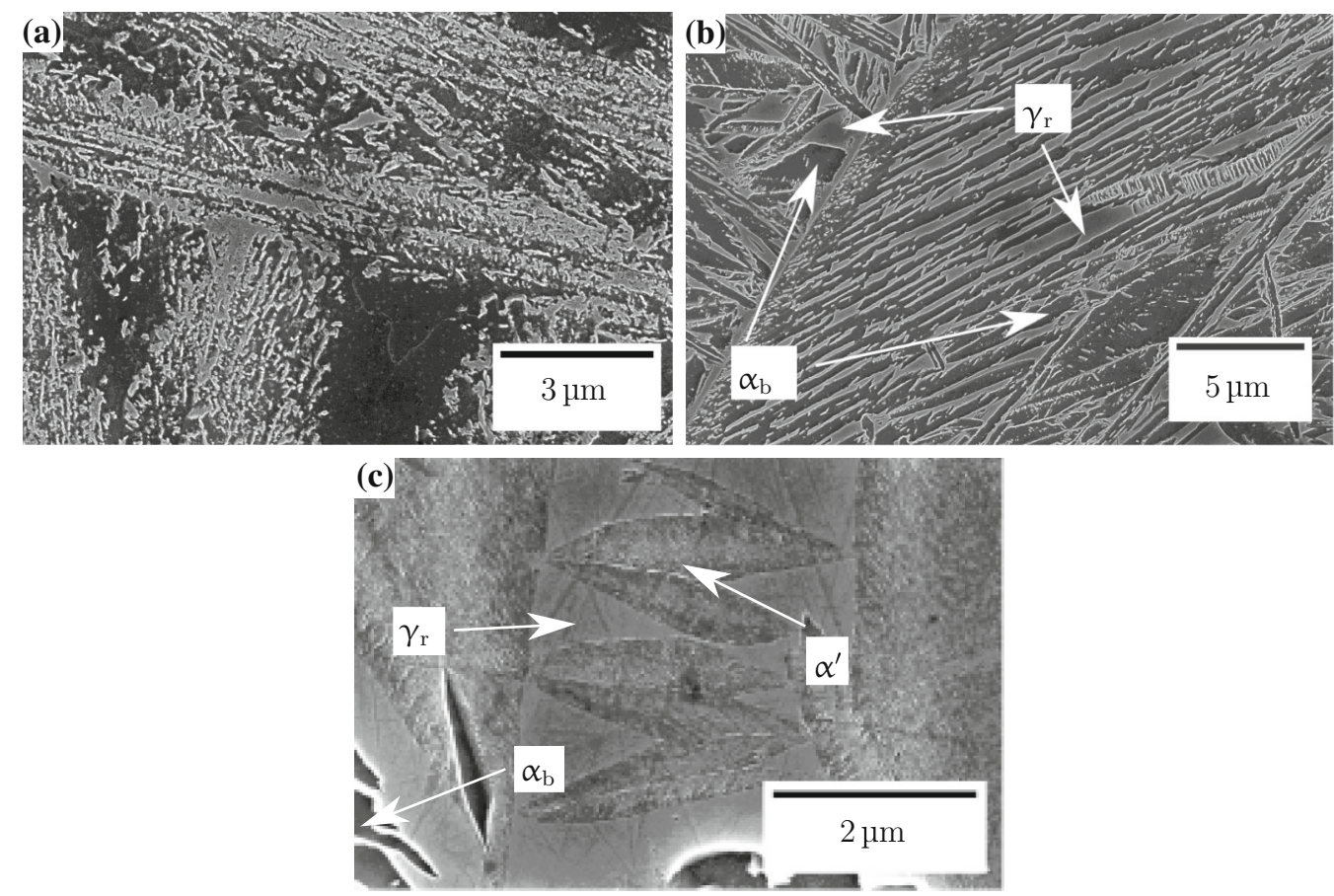

Fig. 8- Scanning electron micrographs of $(a)$ Alloy 1; $(b)$ and $(c)$ Alloy 2. The microstructure of Alloy 1 is radically changed from the as-transformed condition with bright carbides forming in place of retained austenite. Alloy 2 is largely unchanged, save for the formation of martensite in some retained austenite films.

Table IV. Retained Austenite Lattice Parameter, $\boldsymbol{a}_{\gamma_{r}}$, for Both Alloys Measured Before and After Thermal Exposure During Synchrotron Experiments

\begin{tabular}{lccc}
\hline & & $a_{\gamma_{r}} n m$ & Thermally Exposed \\
\cline { 2 - 4 } & As-transformed & Peak & $3.6127 \pm 0.0012$ \\
Alloy 1 & $3.6251 \pm 0.0005$ & $3.6546 \pm 0.0006$ & $3.5998 \pm 0.0005$ \\
Alloy 2 & $3.5992 \pm 0.0005$ & $3.6463 \pm 0.0007$ & \\
\hline
\end{tabular}

The peak lattice parameter, measured at $773 \mathrm{~K}\left(500^{\circ} \mathrm{C}\right)$, is also reported.

coarsening. ${ }^{[44]}$ The larger grain size of Alloy 2 contributes significantly to its lower tensile strength relative to Alloy 1: the fine grain size leads to strengthening via the mechanism of Langford and Cohen. ${ }^{[45]}$ Increasing the grain size in the austenite from 70 to $100 \mathrm{~nm}$ is expected to lead to a reduction in strength of 
Table V. Retained Austenite Volume Fraction, $V_{\gamma_{r}}$ for Both Alloys Measured Before and After Thermal Exposure During Synchrotron Experiments

\begin{tabular}{lcc}
\hline & \multicolumn{2}{c}{$V_{\gamma_{r}}$ (Percent) } \\
\cline { 2 - 3 } & As-transformed & Thermally Exposed \\
\hline Alloy 1 & $29 \pm 3$ & $3.0 \pm 0.7$ \\
Alloy 2 & $28.8 \pm 1.2$ & $20.0 \pm 1.0$ \\
\hline
\end{tabular}

approximately $500 \mathrm{MPa}$. Since austenite is the more ductile phase, its strength will limit that of the alloy. Mechanical properties of the current alloys has been discussed elsewhere. ${ }^{[46]}$

The apparent stability of Alloy 2 may be explained by its high nickel content. It has been observed that the first step in austenite decomposition is the loss of carbon, either to carbides ${ }^{[21]}$ or to defects. ${ }^{[47]}$ While carbon is able to diffuse a significant distance in the tempering process $(4 \mu \mathrm{m}$ in austenite with a high-nickel environment ${ }^{[48]}$, substitutional alloying elements are not. For example, both nickel and cobalt may diffuse approximately $1 \AA$ in 1 hour at $500{ }^{\circ} \mathrm{C}$ and iron $2 \AA^{[49]}$ This means that while the amount of carbon in solid solution may decrease during the tempering experiments, the amount of substitutional solute may not. Examination of the austenite lattice parameters (Table IV) reveals that the loss of carbon from solid solution is much more pronounced in Alloy 1 than Alloy 2: the former undergoes a contraction consistent with the loss of carbon from solid solution whereas the latter does not change significantly. This implies that the dissolved carbon content in the former decreases greatly, while that in the latter undergoes no significant change. ${ }^{[50]}$ The smaller starting lattice parameter of Alloy 2 further indicates that the amount of carbon in solid solution is lower than in Alloy 1. Since the large nickel content of Alloy 2 reduces the driving force for the transformation of austenite to ferrite (Figure 1), the driving force is not sufficient to grow ferrite from the tempered austenite and so the austenite persists throughout tempering and subsequent cooling to room temperature, despite the precipitation of carbides (Table V).

\section{CONCLUSIONS}

Two novel nanocrystalline bainitic steels have been designed and produced. Austenitization at $1273 \mathrm{~K}$ (1000 $\left.{ }^{\circ} \mathrm{C}\right)$ and transformation at $523 \mathrm{~K}\left(250{ }^{\circ} \mathrm{C}\right)$ resulted in a homogeneous, bainitic microstructure consisting of an intimate mixture of bainitic ferrite films, retained austenite films, and retained austenite blocks. Time-resolved in situ synchrotron X-ray diffractometry during tempering of the as-transformed material showed that the austenite persists in Alloy 2 during tempering at 773 $\mathrm{K}\left(500{ }^{\circ} \mathrm{C}\right)$ for 1 hour and throughout subsequent cooling to room temperature. This is the first nanocrystalline bainitic steel in which austenite is not completely lost during tempering and cooling. Such a material, with the combination of strength and toughness typical of similar alloys along with thermal stability has the potential for use in high-temperature engineering applications.

\section{ACKNOWLEDGMENTS}

The authors would like to thank Diamond Light Source for beamtime (proposal EE9880) and the staff of beamline I12 for assistance with the acquisition of the time-resolved data presented in this paper. The authors would also like to thank Rolls-Royce plc and the Engineering and Physical Sciences Research Council for providing funding for the current work (Grant Number RG64823).

\section{OPEN ACCESS}

This article is distributed under the terms of the Creative Commons Attribution 4.0 International License (http://creativecommons.org/licenses/by/4.0/), which permits unrestricted use, distribution, and reproduction in any medium, provided you give appropriate credit to the original author(s) and the source, provide a link to the Creative Commons license, and indicate if changes were made.

\section{REFERENCES}

1. F.G. Caballero, H.K.D.H. Bhadeshia, K.J.A. Mawella, D.G. Jones, and P.M. Brown: Mater. Sci. Technol., 2002, vol. 18, pp. 279-84.

2. H.K.D.H. Bhadeshia: Solid $\rightarrow$ Solid Phase Transform. Inorg. Mater., Proc. Int. Conf., 2005, pp. 469-84.

3. C. García-Mateo, F.G. Caballero, and H.K.D.H. Bhadeshia: J. Phys. IV, 2003, vol. 112, pp. 285-88.

4. C. García-Mateo, F.G. Caballero, and H.K.D.H. Bhadeshia: ISIJ Int., 2003, vol. 43, pp. 1821-25.

5. C. García-Mateo, M.J. Peet, F.G. Caballero, and H.K.D.H. Bhadeshia: Mater. Sci. Technol., 2004, vol. 20, pp. 814-18.

6. M.J. Peet, S.S. Babu, M.K. Miller, and H.K.D.H. Bhadeshia: Scripta Mater., 2004, vol. 50, pp. 1277-81.

7. M.N. Yoozbashi and S. Yazdani: Mater. Sci. Eng. A, 2010, vol. 527, pp. 3200-05.

8. E. Skołek, S. Marciniak, and W.A. Światnicki: Arch. Metall. Mater., 2015, vol. 60, pp. 1-6.

9. H. Hu, H.S. Zurob, G. Xu, D. Embury, and G.R. Purdy: Mater. Sci. Eng. A, 2015, vol. 626, pp. 34-40.

10. F.G. Caballero, M.K. Miller, S.S. Babu, and C. García-Mateo: Acta Mater., 2007, vol. 55, pp. 381-90.

11. F.G. Caballero, M.K. Miller, C. García-Mateo, C. Capdevila, and S.S. Babu: Acta Mater., 2008, vol. 56, pp. 188-99.

12. F.G. Caballero, M.K. Miller, A.J. Clarke, and C. García-Mateo: Scripta Mater., 2010, vol. 63, pp. 442-45.

13. F.G. Caballero, H.-W. Yen, M.K. Miller, J.-R. Yang, J. Cornide, and C. García-Mateo: Acta Mater., 2011, vol. 59, pp. 6117-23.

14. F.G. Caballero, M.K. Miller, and C. García-Mateo: Metall. Mater. Trans. A, 2011, vol. 42A, pp. 3660-68.

15. F.G. Caballero, C. García-Mateo, and M.K. Miller: J. Mater., 2014, vol. 66, pp. 747-55.

16. F.G. Caballero, M.K. Miller, and C. García-Mateo: Acta Mater., 2010, vol. 58, pp. 2338-43.

17. F.G. Caballero, M.K. Miller, C. García-Mateo, J. Cornide, and M.J. Santofimia: Scripta Mater., 2012, vol. 67, pp. 846-49. 
18. F.G. Caballero, M.K. Miller, C. García-Mateo, and J. Cornide: $J$. Alloys Compd., 2013, vol. 577, pp. S626-S30.

19. C.N. Hulme-Smith, I. Lonardelli, A.C. Dippel, and H.K.D.H. Bhadeshia: Scripta Mater., 2013, vol. 69, pp. 409-12.

20. A. Saha Podder and H.K.D.H. Bhadeshia: Mater. Sci. Technol. A, 2010, vol. 527, pp. 2121-28.

21. A. Saha Podder: PhD Thesis, University of Cambridge, U. K., 2011.

22. C.N. Hulme-Smith, I. Lonardelli, M.J. Peet, A.C. Dippel, and H.K.D.H. Bhadeshia: Scripta Mater., 2013, vol. 69, pp. 191-94.

23. R.H. Davies, A.T. Dinsdale, J.A. Robinson, and S.M. Martin: CALPHAD, 2002, vol. 26, pp. 229-71.

24. SGTE (Scientific Group Thermodynamic Europe) thermodynamic database for steels, version 4.2, 2006.

25. PLUS thermodynamic database, version 3.02, National Physical Laboratory, Teddington, U. K., 1993.

26. T. Okumura, T. Sourmail: MTTTData., (University of Cambridge 2004). https://www.msm.cam.ac.uk/map/steel/programs/ MTTTDATA.html Accessed 25 September 2013.

27. T. Sourmail: Neuromat Model Manager. (2004). Accessed 14 September 2013.

28. T. Sourmail, C. García-Mateo: MAP martensite start temperature data library. (University of Cambridge 2004), http://www.msm. cam.ac.uk/map/ data/materials/Ms_data_2004.html. Accessed 3 April 2016.

29. M.J. Peet, H.K.D.H. Bhadeshia: mucg83. (University of Cambridge, 2006), http://www.msm.cam.ac.uk/ map/steel/programs/ mucg83.html. Accessed 14 Aug 2016.

30. H.K.D.H. Bhadeshia and R.W.K. Honeycomb: Steels, 3rd ed., Elsevier, Oxford, U.K., 2006.

31. J.W. Draper: Philos. Mag., 1847, vol. 30, pp. 345-60.

32. C.A. Schneider, W.S. Rasband, and K.W. Eliceiri: Nat. Methods, 2012, vol. 9, pp. 671-75.

33. L.C. Chang and H.K.D.H. Bhadeshia: Mater. Sco. Technol., 1995, vol. 11, pp. 874-82.
34. C. Mack and M.S. Bartlett: Math. Proc. Camb. Philos. Soc., 1956, vol. 52, pp. 246-50

35. M.L. Hart, M. Drakopoulos, C. Reinhard, and T. Connolley: $J$. Appl. Crystallogr., 2013, vol. 46, pp. 1249-60.

36. A.P. Hammersley: Report no. ESRF97HA02T, ESRF, Grenoble, France, 1997.

37. A.P. Hammersley, S.O. Svensson, M. Hanfland, A.N. Fitch, and D. Häusermann: High Press. Res., 1996, vol. 14, pp. 235-48.

38. L. Lutterotti, S. Matthies, H.-R. Wenk: in Proceedings of the 12th International Conference Textures of Materials, vol. 60, J.A. Szpunar ed., 1999, pp. 1599-1604.

39. L. Lutterotti, S. Matthies, and H.-R. Wenk: XNewsl. Commun. Powder Differ., 1999, vol. 21, pp. 14-5.

40. R.A. Young: The Rietveld Method, Oxford University Press, Oxford, U.K, 1993.

41. C. Bellot, P. Lamesle, and D. Delagnes: XActa Metall. Sin., 2013, vol. 26, pp. 553-57.

42. R.E. Schramm and R.P. Reed: Metall. Trans. A, 1975, vol. 6, pp. $1345-51$.

43. G.R. Lehnhoff, K.O. Findley, and B.C. De Cooman: Scripta Mater., 2014, vol. 92, pp. 19-22.

44. C. García-Mateo, M.J. Peet, F.G. Caballero, and H.K.D.H. Bhadeshia: Mater. Sci. Technol., 2004, vol. 20, pp. 814-18.

45. G. Langford and M. Cohen: XMetall. Trans., 1970, vol. 1, pp. 1478-80.

46. C.N. Hulme-Smith and H.K.D.H. Bhadeshia: Mater. Sci. Eng. A, 2017, vol. 700, pp. 714-20.

47. C.Y. Chen, C.C. Chen, and J.S. Lin: XInt. J. Mech. Ind. Sci. Eng., 2014 , vol. 8, pp. 876-79.

48. P. Thibaux, A. Métenier, and C. Xhoffer: Metall. Mater. Trans. A, 2007, vol. 38A, pp. 1169-76.

49. J. Fridberg, L.-E. Törndahl, and M. Hillert: Jernkont. Ann., 1969, vol. 153 , pp. $263-76$.

50. D.J. Dyson and B. Holmes: J. Iron Steel Inst., 1970, vol. 208, pp. 469-74. 